\title{
Long-term care hospitals in Turkey: a review
}

Metin Dincer ${ }^{1}$, Kadriye Kahveci ${ }^{2}$, Cihan Doger ${ }^{3}$ and Ayse Karhan Yarici ${ }^{2}$

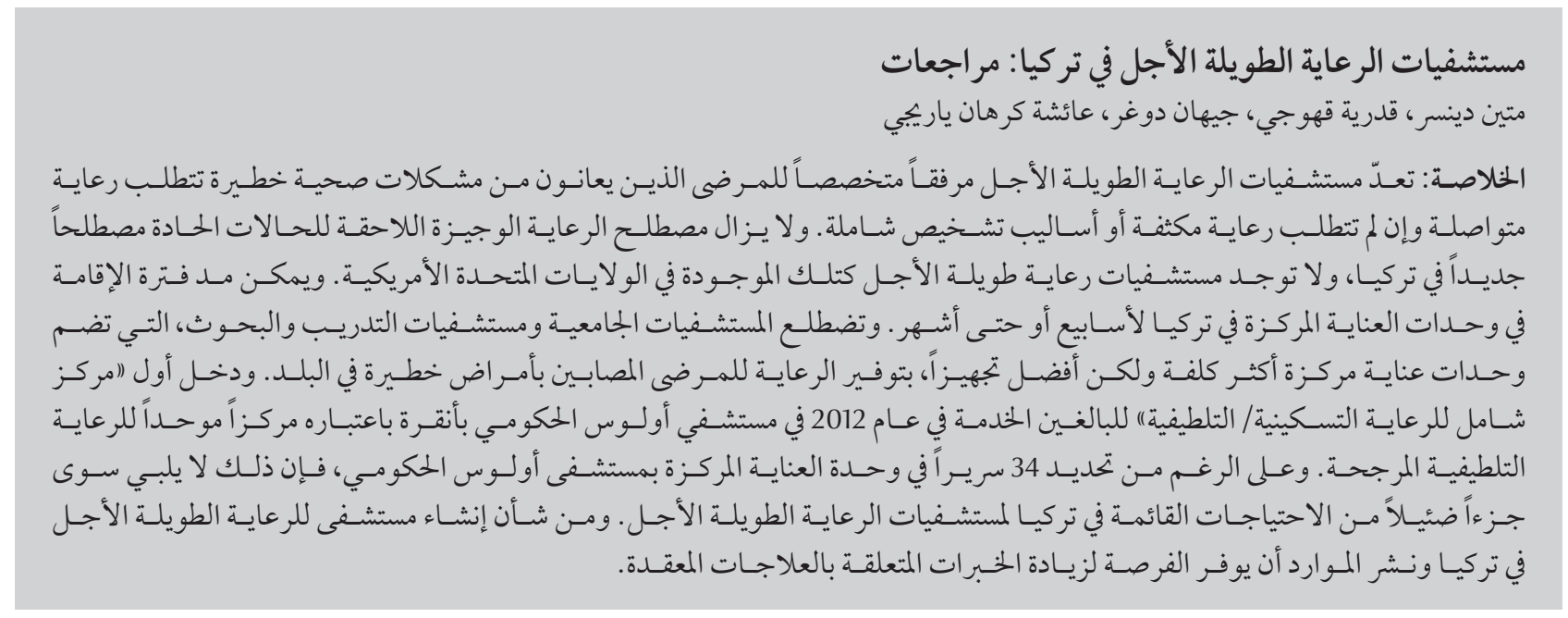

ABSTRACT A long-term care hospital (LTCH) is a specialized facility for patients with serious health problems who require continuous and intensive care but not comprehensive diagnostic methods. LTCHs provide prolonged complex care and wound care in the period following the acute stage of disease. When intensive care unit (ICU) stay is prolonged in the United States of America, the patients may be transferred to an LTCH. Medicare suggests hospitalization $>25$ days in LTCHs. The LTC system in Europe differs from that in other non-European countries and differences are also seen among European countries. In practice, patients who need LTC in Turkey are hospitalized in ICUs. Long term care is a new concept for the Turkish health system and there are no studies on LTCHs in Turkey. A significant proportion of intensive care beds in Turkey are used for long-term hospitalized patients with complex problems. This is a clear waste of resources. The establishment of LTCHs in Turkey would prevent from this waste and provide the opportunity to increase experience of complex treatments.

\section{Centres de long séjour hospitaliers en Turquie : analyse}

Un centre hospitalier de soins de longue durée (CHSLD) est un établissement spécialisé accueillant des patients qui souffrent de graves problèmes de santé et nécessitent des soins continus et intensifs sans avoir à recourir à des méthodes diagnostiques complètes. Les CHLSD fournissent des soins prolongés et complexes ainsi que des soins de plaies dans la période qui suit la phase aigüe de la maladie. Aux États-Unis, lorsque le séjour en unité des soins intensifs est prolongé, les patients peuvent être transférés vers un CHSLD. Medicare recommande une période d'hospitalisation en CHSLD de plus de 25 jours. Le système des CHSLD en Europe est différent de celui qui est établi dans d'autres pays non-européens. On note par ailleurs des différences entre les pays européens eux-mêmes. Dans la pratique, les patients qui ont besoin de soins de longue durée en Turquie sont hospitalisés en unités de soins intensifs. Le concept des soins de longue durée est nouveau dans le système de santé turc et il n'y existe pas d'études sur les CHSLD. Une proportion importante des lits réservés aux unités de soins intensifs en Turquie sont utilisés pour les soins de longue durée aux patients atteints de problèmes complexes. Il s'agit manifestement d'un gaspillage de ressources. La création des CHSLD en Turquie permettra d'éviter ce gaspillage et d'approfondir l'expérience en matière de traitements complexes.

${ }^{7}$ Health Institutions Management, Faculty of Health Sciences, YIldırım Beyazit University, Ankara, Turkey. ${ }^{2}$ Department of Anesthesiology and Reanimation, Ulus State Hospital, Ankara, Turkey. ${ }^{3}$ Department of Anesthesiology and Reanimation, Ankara Ataturk Training and Research Hospital, Ankara, Turkey (Correspondence to: C.Doger: cihandoger@gmail.com)

Received: 23/02/16; accepted 11/01/17 


\section{Introduction}

A long-term care hospital (LTCH) provides post-acute care to a small number of medically complex patients who are more stable than patients in an intensive care unit (ICU), but may still have unresolved underlying complex medical conditions (1). LTCHs provide prolonged complex care and wound care in the period following the acute stage of disease $(2,3)$.

In the United States of America (USA), LTCHs are defined by the Centers for Medicare and Medicaid Services as hospitals where care is provided for patients who need $\geq 25$ days care [1]. In the USA, the average length of hospitalization in acute care hospitals is about 5 days, and in cases of hospitalization $>25$ days $(4,5)$. When intensive care unit (ICU) stay is prolonged in the USA, the patients may be transferred to an LTCH $(1,2,4)$. These patients have usually been discharged from the ICU but still require more care from a care organization, which can be taken in an inpatient rehabilitation centre or at home $(1,4,6)$. Chronic critical patients are an important component of the daily work of every ICU clinician (2). Although chronic critical patients comprise only $10 \%$ of admittances to the ICU in the USA, they use $40 \%$ of the IC resources $(2,7)$. Patients with chronic critical illness those who exhibit complex condition that often result in ongoing respiratory failure (8). It has been proposed to establish a special care unit specially designed to meet the needs of patients with chronic critically ill conditions (9). The care requirements of patients with complex medical problems that continue for a long period are thought to be better provided by the personnel and resource management in LTCHs in the USA $(3,9,10)$. The majority of patients in LTCHs require long-term mechanical ventilation following an acute disease (10). At the same time close airway, monitoring must be applied with continuous inotropic and vasopressor support (6). In some LTCHs, treatment of advanced pressure wounds is applied $(1,6)$. In practice, patients who need LTC in Turkey are hospitalized in ICUs. LTC is a new concept for the Turkish health system and there are no studies on LTC or LTCHs in Turkey. This review aims to draw attention to the need for and importance of LTCHs in Turkey.

\section{General features of LTCH}

Patients in LTCHs are generally defined as chronic critical patients $(2,4)$. This term was first used in 1985 by Girard and Raffin (11). It is used in the literature to describe patients who have overcome the first stage of critical disease but continue to require acute intensive care $(1,10)$. LTCHs were first aimed at patients who needed long-term mechanical ventilation (12). However, a wide range of patients constitutes those admitted to LTCHs (Table 1) (13). Patients admitted to LTCHs comprise those with a complex status, multiple comorbidities and acute medical needs (6). Patients who require mechanical ventilation have comorbidity such as respiratory failure, recent surgical intervention, gastrostomy tube, total parenteral nutrition, urinary bladder or central venous catheter, pressure wounds and malnutrition $(6,10,14)$.

In some European countries, LTCHs are integrated within the healthcare system for post-acute care (PAC) and located in healthcare institutions $(15,16)$. The LTC system in Europe differs from that in other nonEuropean countries and differences are also seen among European countries (15). Cash-for-care systems were first implemented in Europe in the 1970s and became widespread in the 1990s, and are programmers by which care services can be purchased according to the healthcare insurance premiums paid by an individual (16). The rationale behind cash-for-care systems was that alternative healthcare services could be freely selected by the individual (16). As the financial costs of the hospital and care institutions were met by the patient's insurance, competition to provide the best service started between care institutions $(15,16)$.

In Germany, it is mandatory for insurance to include LTC, pay-as-you-go is included in the national insurance scheme at the rate of $90 \%$ and the remainder is covered by private insurance (17). Patients pay according to the 3-stage definition of dependence of national insurance (18). In Germany, the term long term specifies a need for $>$ 90 minutes assistance in at least 2 daily activities for $>6$ months (17). Consequently, the higher the level of dependence, the greater the need for care and the institutional share of the care costs increases (18).

In the United Kingdom of Great Britain and Northern Ireland, Italy and Spain, long-term healthcare services are provided by the National Health Service (19). Social services provided for elderly people are financed by national and local taxation and charges to the individuals receiving care (19). Thus, healthcare services are basically financed by central taxation, but debate about the financing of LTC continues (19).

In the United Kingdom, geriatric care is provided by the public and private sectors, with more than half the geriatric healthcare beds in independent care homes (20). Since the mid-1980s the number of care homes has increased 7-fold, and all require personnel, monitoring, applications and finance (20).

In Japan, although LTC insurance was originally planned to include the geriatric age group, it was later extended to the 40-64 years age group (21). It was planned that this age group would pay double insurance premiums because it was thought that there could be problems with payments for conditions 


\begin{tabular}{|c|c|c|c|}
\hline $\begin{array}{l}\text { MS-LTC- } \\
\text { DRG }\end{array}$ & Description & Discharges & Percentage \\
\hline 207 & Respiratory system diagnosis with ventilator support $>96 \mathrm{~h}$ & 15842 & 11.3 \\
\hline 189 & Pulmonary edema and respiratory failure & 14036 & 10.0 \\
\hline 871 & Septicemia or severe sepsis without ventilator support $>96 \mathrm{~h}$ with MCC & 8954 & 6.4 \\
\hline 177 & Respiratory infections and inflammations with MCC & 4546 & 3.2 \\
\hline 592 & Skin ulcers with MCC & 4004 & 2.8 \\
\hline 208 & Respiratory system diagnosis with ventilator support $<96 \mathrm{~h}$ & 3060 & 2.2 \\
\hline 949 & Aftercare with CC/MCC & 3060 & 2.2 \\
\hline 539 & Osteomyelitis with MCC & 2605 & 1.9 \\
\hline 190 & Chronic obstructive pulmonary disease with MCC & 2466 & 1.8 \\
\hline 193 & Simple pneumonia and pleurisy with MCC & 2259 & 1.6 \\
\hline 919 & Complications of treatment with MCC & 2200 & 1.6 \\
\hline 559 & Aftercare, musculoskeletal system and connective tissue with MCC & 2190 & 1.6 \\
\hline 682 & Renal failure with MCC & 2142 & 1.5 \\
\hline 314 & Other circulatory system diagnoses with MCC & 2061 & 1.5 \\
\hline 862 & Postoperative and post-traumatic infections with MCC & 2053 & 1.5 \\
\hline 570 & Skin debridement with MCC & 1965 & 1.4 \\
\hline 870 & Septicemia or severe sepsis with ventilator support $>96 \mathrm{~h}$ & 1928 & 1.4 \\
\hline 166 & Other respiratory system OR procedures with MCC & 1899 & 1.4 \\
\hline \multirow[t]{2}{*}{4} & Tracheostomy with ventilator support $>96 \mathrm{~h}$ or primary diagnosis except & & \\
\hline & face, mouth, and neck without major OR procedure & 1840 & 1.3 \\
\hline 291 & Heart failure and shock with MCC & 1749 & 1.2 \\
\hline 853 & Infectious and parasitic diseases with OR procedure with MCC & 1561 & 1.1 \\
\hline 602 & Cellulitis with MCC & 1523 & 1.1 \\
\hline 603 & Cellulitis without MCC & 1487 & 1.1 \\
\hline 981 & Extensive OR procedure unrelated to principal diagnosis with MCC & 1455 & 1.0 \\
\hline \multirow[t]{3}{*}{371} & Major gastrointestinal disorders and peritoneal infections with MCC & 1424 & 1.0 \\
\hline & Top 25 MS-LTC-DRGs & 88309 & 62.9 \\
\hline & Total & 140496 & 100.0 \\
\hline
\end{tabular}

MS-LTC-DRGs are the case-mix system for LTCHs. Columns may not sum due to rounding. CC = complication or comorbidity; $L T C H=$ long-term care hospital; MCC = major complication or comorbidity; MS-LTC-DRG=Medicare severity long-term care diagnosis-related group; OR=operating room. Source: MedPAC analysis of Medicare provider analysis and review data from Centers for Medicare and Medicaid Services.

that are not related to ageing but still require LTC, such as mental diseases and traffic accidents (21). However, the LTC costs of this age group only constitute $4 \%$ of all LTC costs (21). In 2000, the Japanese Government implemented a new LTC insurance application and made a series of revisions due to limitations and payment problems in a 5-year implementation period (21). Revisions to be made later focused on the need for LTC insurance to include the costs of all age groups and conditions of disability (21). In 2007 there were 25 LTC facilities in Japan and this number increased to 31 in 2008 (22).

In Canada, LTC facilities or care homes provide long-term accommodation and care for dependent individuals who require care because of medical, physical or mental disability $(23,24)$. As in other western countries, LTC facilities are publicly financed, with the amounts varying among the provinces $(23,24)$. In recent years, there has been a disproportionate increase in the number of publicly financed beds and the government has urged more economic spending of public funds used for nursing homes (24).

With the currently increasing elderly population and developments in intensive care, there is expected to be an increase in diseases requiring chronic intensive care and increased consumption of healthcare resources $(25,26)$. Throughout the world, but especially in the USA, projects have been developed related to healthcare costs and resource management $(25,26)$. Despite the rapid growth of LTCHs, little is still known about the quality of results and 
cost-effectiveness of the care given in this category $(1,2)$.

In the USA, although the treatment of most patients is maintained at home or in short-term hospitals, the majority of these patients who require complex medical treatment that cannot be provided at home or in a care home, and patients who require intensive care are transferred to long-term acute care hospitals (6). With the rapid growth of LTCHs since 1983, the situation has eased somewhat and these institutions have started to accept patients requiring long-term mechanical ventilation, and have been able to focus on weaning patients from long-term mechanical ventilation (2,3). Ideally, the LTCH approach provides the basis for rehabilitation of patients, with a multidisciplinary approach comprising elements such as LTC specialist nurses, respiratory therapists, dieticians, physiotherapists, speech therapists, occupational therapists and experienced discharge planners (27). Some centres include a psychiatrist and clinical psychologist in the team and are thus helpful in meeting the emotional needs of the patients families (27).

\section{History}

The Medicare System is the National Healthcare Insurance System in the USA and provides healthcare insurance for employees and those who pay into the system (4). Until the 1980s, rehabilitation and recovery services following acute care were both inexpensive and less invasive (28). Historically, postoperative acute care was a small portion of Medicare expenses (28). In 1981, acute care started to be incorporated into long-term acute care as a result of extraordinary costs of $\sim$ US\$ 15 billion for ICU patients $(14,29)$. The main source of these costs was thought to be the excessively high costs of acute care hospitals related to groups with an extended hospital stay because of the difficulty of weaning from mechanical ventilation (29). Therefore research commenced into how costs could be reduced for the care of patients requiring long-term acute care $(28,29)$. In 1982, with the Tax Equivalence and Financial Responsibility Agreement (TEFRA) and also LTCHs were designated by Medicare to form a specific payment method for LTC (28).

By providing financial support to Medicare for the care of chronic critical patients since 1983, the Healthcare Financial Administration in the USA has enabled the opening of many LTCHs (30). Following the application of prospective payments by Medicare to acute hospitals in 1984, the payments made to PAC services grew rapidly (28). Most of this growth was to provide nursing services to care institutions and at home (28). Initially, a small percentage of the total Medicare expenses was allocated for LTCHs (28). Over time, LTCHs have become one of the most rapidly growing segments of the healthcare system (31). The oldest-established LTCH in the USA was developed from tuberculosis and chronic disease hospitals (28). The money allocated by Medicare for LTCHs between 1988 and 1996 increased by an average annual growth rate of $31 \%$ from US\$ 0.2 billion to 1.7 billion and since 1997,200 hospitals have been licensed as LTCHs by Medicare (28).

In 1997, the primary payment of Medicare at a rate of $71 \%$ was for LTC. By exempting LTCHs from the prospective payment system, TEFRA took the mean payment as the basis of costs (28). These financial incentives increased the discharge of patients hospitalized in long-term acute care hospitals to LTCHs (28). By starting the growth of LTCHs as soon as these incentives became clear, the Medicare Payment Consultation Commission reported that the 90 LTCHs in 1990 had increased to 363 in 2005 (5). In the 2003 financial year, Medicare applied prospective payments for LTCHs for partial financial control and reorganized LTC diagnosis groups defined according to diagnosis rather than by costs applied according to TEFRA payments $(5,14)$. While state hospitals were under pressure to be profit-driven at the start of the 1980s, in 2004 the majority of LTCHs were profitable (5).

In the USA, patients who have not fully recovered after acute disease and require care are provided for by $\mathrm{PAC}$ units within nursing care institutions, home healthcare institutions, inpatient rehabilitation institutions and LTCHs (13,32). PAC expenses rose from US\$ 29.3 billion in 2001 to US\$ 58.8 billion in 2013; of which, LTCHs were a small part (US\$ 5.2 billion) and the largest portion was for nursing care institutions at US\$28.8 billion (32).

The number of LTCHs rose from 277 in 2003 to 412 in 2010 and during that time, Medicare expenses increased from US\$ 2.7 billion to US\$ 5.2 billion (4). Although the reasons for this increase are complex, the primary factor seems to be an increasing need for mechanical ventilation because of the increasing ageing population, and with developments in treatment methods, mortality has decreased but invalidity has increased (31). A secondary reason is that in the USA, the prospective financial incentives given for LTCHs have increased the financial burden on the Medicare system and created a significant healthcare policy problem $(13,33,34)$.

In Europe, LTC is defined more as care for geriatric patients aged $>65$ years, either in their own home or in a care home, and as in the USA, acute care required for patients after intensive care is defined as long-term acute care $(4,17)$. In Turkey, elderly care is seen as a religious obligation, therefore, in the majority of cases the burden is borne by the family. There is a lower need for geriatric care facilities in Turkey but there is a requirement for LTCHs for monitoring the elderly population in acute care facilities. To resolve problems related 
to LTC in Turkey, there is a need to establish LTCH units, and to achieve this, the USA model would seem to be the most appropriate.

\section{LTCHs in Turkey}

With the increasing elderly population in Turkey, there has also been an increase in chronic diseases (35). In recent years, there has been an improvement in the quality of care in ICUs in Turkey and an increase in the number of units. According to the 2014 statistical data of the Ministry of Health, the number of ICU beds increased from 2214 in 2002 to 28572 in 2014; an increase of $\sim 13$-fold (Figure 1) (35).

Standardization of ICUs was started in 2005 with quality criteria defined by the Ministry of Health and in 2007 ICUs were categorized into 3 levels according to the technical equipment and number of physicians and nurses. According to these criteria, ICUs providing monitoring of the most serious patients were classified as $3 \mathrm{rd}$ level (36). The charges to be paid for services in the healthcare sector in Turkey are defined by the Social Security Institution (SSI). Payments to ICUs have been made since 2007 within the Healthcare Application Declaration programmer created by the SSI (37). Due to contested problems related to repayments over time, various corrections were made with an additional regulation. In 2008, payment at the fee for service was started instead of the diagnosis related group (DRG) (38). With later improvements, the system returned to payment based on the DRG (37). With continuous changes being made by the SSI to the implementation of payments for ICU charges, the Healthcare Application Declaration is updated frequently. PAC is still a new term in Turkey and there are no LTCHs as in the USA. Although the SSI defines the basis of the healthcare system, the difficult conditions related to the period of stay in ICUs have not been defined. However, prolonged the stay in the ICU, the charges are paid by the SSI in Turkey (38). Due to the development of ICU conditions, patients are supported with advanced equipment and medication. As the decisions of "do not resuscitate" and "terminate treatment" do not yet have a sufficient place within the legal system and families are not aware of these, ICU stay can be prolonged for several weeks or even months. The care of patients with serious diseases in Turkey is provided by university and training and research hospitals, which have costlier, better-equipped ICUs. A study using the database of DRG in Turkey has reported data related to 5784 patients in the adult 1st, 2 nd and 3rd level ICUs of 73 hospitals between June 2014 and May 2015 (39). It showed that 41.5\% of ICU patients were aged $>65$ years and $3.5 \%$ had an ICU stay $>30$ day. It was also seen that the rate of stay $>30$ days in a surgical ICU, which are $3 \mathrm{rd}$ level, was 11.4\% (39). When the 2014 data are taken as the basis, it can be concluded that of the 18.160 adult intensive care beds, 2070 (11.4\% of 18.160 ) beds should be in LTCHs.

However, it can be estimated that the actual number should be higher, as the data of the above-mentioned study were not examined according to the level of ICU. As patients with a prolonged stay gain more benefit from ICU

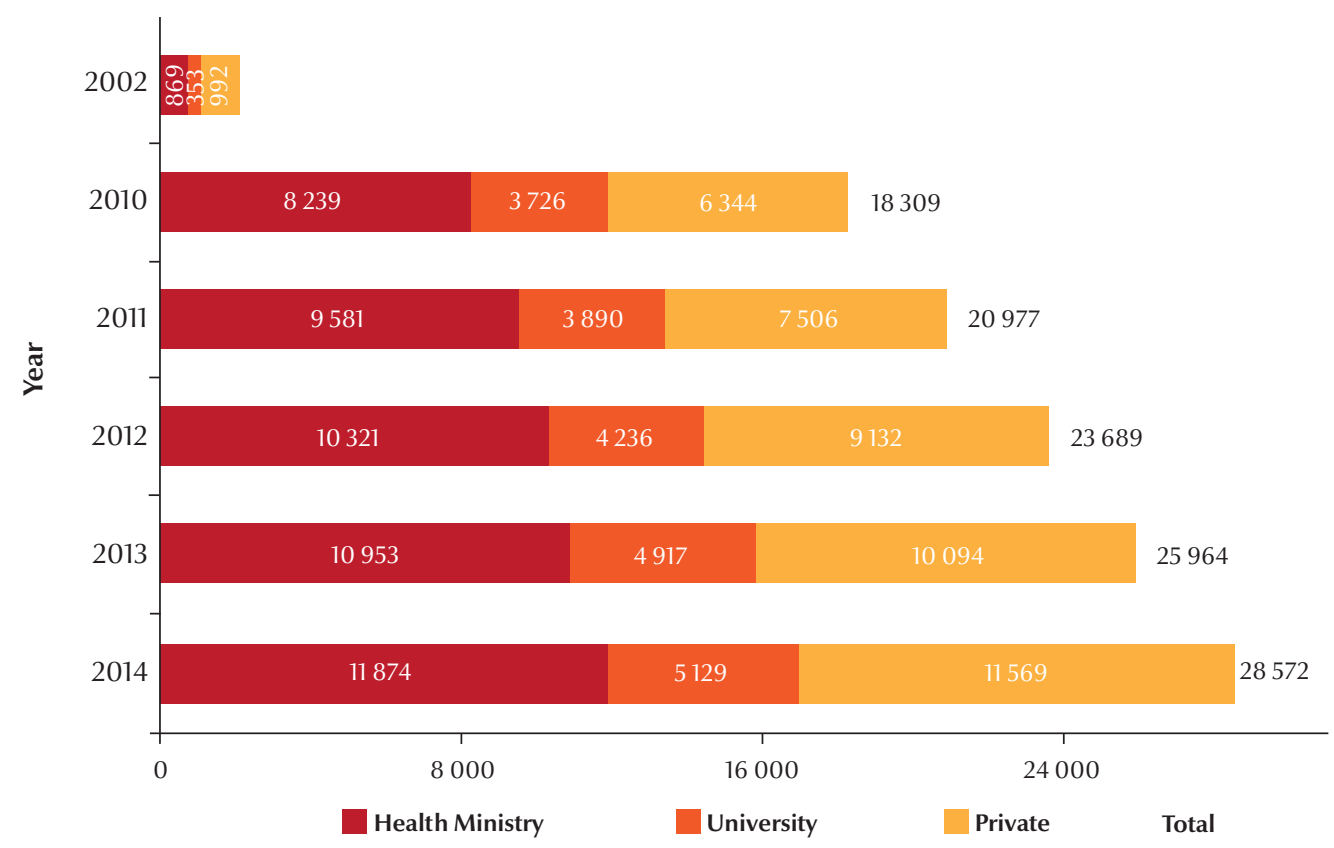

Figure 1 Total number of intensive care beds in Turkey between 2002 and 2014 (28) 
resources than those in acute care, this could prevent use by potential patients. In addition, ICUs that are organized for acute care remain insufficient in complex cases requiring experience such as resistant infections, physiotherapy, pressure wound care and weaning from prolonged ventilator treatment. The 1 st palliative care service in Turkey started in 2007 at Ankara Oncoloy Hospital, thus placing complex patient care on the national agenda.

Within the scope of the Palya-Turk Project, initiated by the Ministry of Health in 2010 (40) the 1st Comprehensive Palliative Care Centre for adults came into service on 6 December 2012 at Ankara Ulus State Hospital as a palliative-care-weighted single centre. At the same time, as the decisions of "do not resuscitate" and "terminate treatment" still do not have a sufficient place within the legal system and families are not aware of these, continuation of terminal care of PAC patients is provided in ICUs. Although 34 beds in the Ulus State Hospital ICU have been designated as the intensive care service, this only meets a small part of the requirement in Turkey for LTCHs. By transferring critical patients who are not recovering and have a prolonged treatment period in the better-equipped ICUs of university and training and research hospitals to the ICU in Ankara Ulus State Hospital, service is provided without shortening the hospitalization period. Thus, the high-cost ICU beds in better-equipped hospitals can be used more effectively and lower-cost care can be provided for patients requiring long-term complex care without transferring to home care or rehabilitation centres. Although the quality and cost-effectiveness of the care have not yet been fully revealed, that the ICU beds in university and training and research hospitals in Ankara are not blocked by long-term patients can provide a better chance of full recovery for acute serious patients with acute intensive care over a short period.

In conclusion, the concept of LTCHs is still unknown in Turkey. A significant proportion of intensive care beds in Turkey are used for long-term hospitalized patients with complex problems. This is a clear waste of resources. The establishment of LTCHs in Turkey and the spread of resources would prevent this waste and provide the opportunity to increase experience of complex treatments. This review is believed to be the first article to determine the status of LTCHs in Turkey. Thus, the findings can be considered to be of value in the future establishment of LTCHs, which are widespread globally, and would be useful in providing a service for both patient comfort and in terms of national socioeconomic welfare.

\section{Funding: None.}

Competing interests: None declared.

\section{References}

1. Defining long-term care hospitals. In: Report to the Congress: new approaches in Medicare. Washington. DC: Medicare Payment Advisory Commission; 2004:121-32 (http://67.59.137.244/publications/congressional_reports/ June04_ch5.pdf, accessed 4 May 2017).

2. Scheinhorn DJ, Hassenpflug MS, Votto JJ, Chao DC, Epstein SK, Doig GS, et al. Ventilator-dependent survivors of catastrophic illness transferred to 23 long-term care hospitals for weaning from prolonged mechanical ventilation. chest Journal. 2007 Jan;131(1):76-84. PMID:17218559

3. Carson SS. Know your long-term care hospital. Chest. 2007 Jan;131(1):2-5. PMID:17218547

4. What are long-term care hospitals? Revised September 2015. Centers for Medicare and Medicaid Services (CMS Product No. 11347; http://www.medpac.gov/docs/default-source/ reports/march-2012-report-to-the-congress-medicare-payment-policy.pdf?sfursn=0, accessed 4 May 2017)

5. Federal Register; Part 2, D.o.H.a.H.S., Centers for Medicare \& Medicaid Services, Medicare program; prospective payment system for long-term care hospitals RY 2007: annual payment rate updates, policy changes, and clarification. Final rule. Fed Regist, 2006. 71(92): p. 27797-939.

6. Carson SS, Bach PB, Brzozowski L, Leff A. Outcomes after long-term acute care: an analysis of 133 mechanically ventilated patients. Am J Respir Crit Care Med. 1999 May;159(5 Pt 1):1568-73. PMID:10228128

7. Wagner DP. Economics of prolonged mechanical ventilation. Am Rev Respir Dis. 1989 Aug;140(2 Pt 2):S14-8. PMID:2669583
8. Long-term care hospitals payment system 2015. (http://www. medpac.gov/documents/payment-basics/long-term-carehospitals-payment-system-15.pdf?sfursn=0)

9. Daly B, Rudy E, Thompson K, Happ M. Development of a special care unit for chronically critically ill patients. Heart \& lung: the journal of critical care 1991 Jan;20(1):45-51. PMID:1988392

10. Munoz-Price, L.S., Long-term acute care hospitals. Clin Infect Dis 2009. 49(3):438-43. PMID: 19548836

11. Girard K, Raffin TA. The chronically critically ill: to save or let die? Respir Care. 1985 May;30(5):339-47. PMID:10315661

12. Lundberg JA, Noll ML. The long-term acute care hospital: a new option for ventilator-dependent individuals. AACN Clin Issues Crit Care Nurs. 1990 Aug;1(2):280-8. PMID:2119667

13. Long-term care hospital services Report to the Congress Medicare Payment Policy March 2014 http://www.medpac. gov/docs/default-source/reports/mar14_entirereport.pdf. accessed 4 May 2017

14. Eskildsen MA. Long-term acute care: a review of the literature. J Am Geriatr Soc. 2007 May;55(5):775-9. PMID:17493200

15. Leichsenring K. Developing integrated health and social care services for older persons in Europe. Int J Integr Care. 2004;4:e10. PMID:16773149

16. Da Roit B, Le Bihan B. Similar and yet so different: cash-for-care in six European countries' long-term care policies. Milbank Q. 2010 Sep;88(3):286-309. PMID:20860573

17. Comas-Herrera A, Wittenberg R, Costa-Font J, Gori C, Di Maio A, Patxot $\mathrm{C}$, et al. Future long-term care expenditure in Germany, Spain, Italy and the United Kingdom. Age- 
ing Soc. 2006;26:285-302 (https://doi.org/10.1017/ S0144686X05004289).

18. Schulz E. Determinants of institutional long-term care in Germany. Assessing Needs of Care in European Nations; 2012 (ENEPRI Research Report No. 115; http://www.ancien-longtermcare.eu/sites/default/files/RRNo115_ANCIENWP6_SchulzDeterminantsofLTCinGermany.pdf, accessed 4 May 2017).

19. Comas-Herrera A, Costa-i-Font J, Gori C, di Maio A, Patxot C, Pickard L, et al. European Study of Long-Term Care Expenditure: Investigating the sensitivity of projections of future longterm care expenditure in Germany, Spain, Italy and the United Kingdom to changes in assumptions about demography, dependency, informal care, formal care and unit costs. 2003 (Report to the European Commission, Employment and Social Affairs DG. Grant number VS/2001/0272. PSSRU Discussion Paper 1840; http://ec.europa.eu/employment_social/socprot/healthcare/Itc_study_en.pdf, accessed 4 May 2017).

20. Kerrison SH, Pollock AM. Regulating nursing homes: caring for older people in the private sector in England. BMJ. 2001 Sep 8;323(7312):566-9. PMID:11546707

21. Ikegami N. Rationale, design and sustainability of longterm care insurance in Japan - in retrospect. Soc Policy Soc. 2007 Jul;6(3):423-34 (https://doi.org/10.1017/ S1474746407003739).

22. Okamoto E, Miyamoto M, Hara K, Yoshida J, Muto M, Hirai A, et al. Integrated care through disease-oriented clinical care pathways: experience from Japan's regional health planning initiatives. Int J Integr Care. 2011 Jan;11(Spec 10th Anniversary Ed):e125. PMID:22128281

23. Berta W, Laporte A, Valdmanis V. Observations on institutional long-term care in Ontario: 1996-2002. Can J Aging. 2005 Spring;24(1):70-84. PMID:15838827

24. Cohen M, Murphy J, Nutland K, Ostry A. Continuing care renewal or retreat? $\mathrm{BC}$ residential and home health restructuring 2001-2004. Canadian Centre for Policy Alternatives BC Office; 2005 (http://policyalternatives.ca/sites/default/files/ uploads/publications/BC_Office_Pubs/bc_2005/continuing_care.pdf, accessed 4 May 2017).

25. Kahn JM, Angus DC. Health policy and future planning for survivors of critical illness. Curr Opin Crit Care. 2007 Oct;13(5):5148. PMID:17762228

26. Macintyre NR. Chronic critical illness: the growing challenge to health care. Respir Care. 2012 Jun;57(6):1021-7. PMID:22663975

27. Scheinhorn DJ, Chao DC, Hassenpflug MS, Gracey DR. PostICU weaning from mechanical ventilation: the role of long- term facilities. CHEST Journal. 2001 Dec;120(6 Suppl):482S-4S. PMID:11742970

28. Thomas DC, Kreizman IJ, Melchiorre P, Ragnarsson KT. Rehabilitation of the patient with chronic critical illness. Crit Care Clin. 2002 Jul;18(3):695-715. PMID:12140920

29. Liu K, Baseggio C, Wissoker D, Maxwell S, Haley J. Longterm care hospitals under Medicare: facility-level characteristics. Health Care Financ Rev. 2001 Winter;23(2):1-18. PMID:12500335

30. Hotes LS, Kalman E. The evolution of care for the chronically critically ill patient. Clin Chest Med. 2001 Mar;22(1):1-11. PMID:11315448

31. Carson SS, Bach PB. The epidemiology and costs of chronic critical illness. Crit Care Clin. 2002 Jul;18(3):461-76. PMID:12140908

32. Kahn JM, Benson NM, Appleby D, Carson SS, Iwashyna TJ. Long-term acute care hospital utilization after critical illness. JAMA. 2010 Jun 9;303(22):2253-9. PMID:20530778

33. Health Care Spending and the Medicare Program. 2016. (http://www.medpac.gov/docs/default-source/data-book/ june-2016-data-book-health-care-spending-and-the-medicare-program.pdf, accessed 4 May 2017).

34. Kahn JM, Werner RM, David G, Ten Have TR, Benson NM, Asch DA. Effectiveness of long-term acute care hospitalization in elderly patients with chronic critical illness. Med Care. 2013 Jan;51(1):4-10. PMID: 22874500

35. Koranne R. The role of the long-term acute care hospital. Minn Med. 2011 Sep;94(9):38-40. PMID: 22039683

36. T.C. Sağlık Bakanlığı Sağlık istatistikleri yıllığı 2014, http://www. saglik.gov.tr/TR/dosya/1-100380/h/tryillik.PDF accessed 4 May 2017).

37. Standarts of Intensive Care Units Resmi Gazete, 2007. (http:// www.resmigazete.gov.tr/eskiler/2007/05/20070525M1-3. htm. accessed 4 May 2017).

38. Sağlik Uygulama Tebliği. Resmi Gazete, 2007. (http://www. resmigazete.gov.tr/eskiler/2007/05/20070525M1-3.htm. accessed 4 May 2017).

39. Sağlik Uygulama Tebliği. Resmi Gazete, 2010. 27532 (http:// www.resmigazete.gov.tr/eskiler/2010/03/20100325M1-1. $\mathrm{htm}$. accessed 4 May 2017).

40. Sülekli HE. Küçük A. T.C. Sağlık Bakanlığı Türkiye Kamu Hastaneleri Kurumu Yoğun Bakım Üniteleri Araștırması, http:// www.tkhk.gov.tr/Dosyalar/4292ab83043844b7ale68694155 679b0.pdf 2015. 